\title{
Hyviä rypsisatoja pienellä kylvösiemenmäärällä
}

\author{
Heikki Harmanen
}

SeAMK, Maa- ja metsätalous, Ilmajoentie 525, 60800 Ilmajoki, heikki.harmanen@seamk.fi

\section{Tiivistelmä}

Öljykasvien viljelyalan toivotaan lisääntyvän jopa 200000 hehtaariin, mutta kesäksi 2011 viljelyala puoliintui edellisestä vuodesta ollen 79000 ha. Rypsin viljely on laajentunut uusille alueille, mutta lupaavan alun jälkeen satotasot ovat viimeisen 15-20 vuoden aikana kuitenkin laskeneet. Kasvien hintavaihteluiden lisäksi viljelyintoa on vähentynyt jopa alle 1000 kg/ha jääneet sadot. Syyksi on esitetty: mm. Lisääntynyttä tautipainetta, viljelykierron lyhyyttä ja uusien lajikkeiden satoherkkyyttä kukintavaiheen lämpötiloille. Tutkimuksen alkaessa v. 2009 rypsin tavanomainen kylvösuositus oli n. 8-10 kg/ha (300-350 kasvia/m²). Kyseinen siemenmäärä voi heikosti taimettuvilla savimailla olla sopiva. Kyseisellä siemenmäärällä voi muodostua liian tiheä kasvusto hikevillä hietamailla ja multamailla. Tiheässä kasvustossa mikroilmasto on kostea ja tautiriski kasvaa. Johtaako kilpailu honteloihin ja pitkiin yksilöihin? Pohjanmaalla moni viljelijä käyttääkin siementä 6-8 kg/ha ja pienistä, jopa 4 kg/ha kylvömääristä on hyviä kokemuksia.

Ilmajoella koulutilalle vuonna 2009 aloitetussa peltomittakaavassa tehtävässä tutkimuksessa halutaan selvittää, voidaanko helposti taimettuvilla (koululla mHHt) mailla käyttää pienempää kylvösiemenmäärää ja sitä, miten pienempi taimimäärä vaikuttaa kasvuston kehitykseen, rakenteeseen ja satokomponenttien muodostumiseen ja satoon sekä pahkahomeen esiintymiseen ja kasvuston mikroilmastoon (ei esitellä tässä).

Kaikkia tässä tutkimuksessa toteutuneita kasvustotiheyksiä (55-249 kpl/m2) Ilmajoella voidaan pitää suositeltuun tavoitetiheyteen nähden harvana. Koelohkojen keskisadot (9\% kosteus) olivat 1640-2 $690 \mathrm{~kg} / \mathrm{ha}$ ja ne ovat alueen keskisatoja korkeampia. Harvassa kasvustossa tyvet olivat jopa $3 \mathrm{~mm}$ paksumpia kuin tiheimmässä kasvustossa, sivuhaarojen lukumäärä ja niiden litujen lukumäärä kompensoivat yksilömäärää. Vuonna 2009 joka toisesta vantaasta kylvetyllä pienimällä kylvömäärällä roskaisuus oli kaksinkertainen muihin koejäseniin nähden. Puintikosteus ja sadon laatu eivät eronneet toisistaan.

Kasvustojen korkeudet vaihtelivat vuosittain, mutta kasvutiheyksien välillä ei ollut eroja. Tiheässä kasvustossa pääversojen pituuskasvu alkoi aikaisemmin. Harvassa kasvustossa kehitys eteni tiheää hieman hitaammin ja kasvusto tuleentui noin viikkoa myöhemmin. Juurien paino oli harvassa kasvustossa tiheämpää suurempi.

Pahkahomeen pahkoja löytyi vuonna 2010 keskimäärin 6-8 kpl/m² kun pahkahome oli torjuttu ja torjumattomilta koejäseniltä harvimmasta kasvustosta $15 \mathrm{kpl} / \mathrm{m}^{2}$ ja muista kasvustoista $25-27 \mathrm{kpl} / \mathrm{m}^{2}$. Vuonna 2011 tilanne oli Ilmajoella lakokasvustossa samansuuntainen, Ylistarossa oli lisäkoe multamaalla, siellä koko ala ruiskutettiin ja pahkoja löytyi 29 ja 32 kpl/m². Kesällä 2011 heinäkuun loppupuolen ja elokuun runsaat sateet pitivät maan kosteana ja kasvusto lakoontui Ilmajoella lähes kauttaaltaan. Kasvusto oli kuitenkin taipuneena ja sen korkeus oli 20-30 cm. Ylistarossa multamaa kasvusto meni lakoon lähes maata myöden, korkeus oli10-20 cm.

Tutkimuksen aikana viljelyohjeita on päivitetty ja yleissuosituksena siemenmääräksi esitetään 6-10 kg/ha (300 kpl/m²), hyvissä olosuhteissa suositellaan käytettäväksi 4-5 kg/ha ja taulukossa esitetään jopa pienempiäkin kylvömääriä ja kasvustotiheyksiä (Öljykasvinviljelijän opas 2011). Nykyisillä työkoneilla muokkaus- ja kylvötyöt sujuvat tehokkaasti ja siemen saadaan suotuisiin kasvuoloihin. Tutkimuksen perusteella helposti taimettuvilla mailla (olosuhteissa) on syytä rohkeasti kokeilla pienempiä kylvömääriä, niillä voidaan turvallisesti tavoitella taimitiheyttä $150 \mathrm{kpl} / \mathrm{m}^{2}$. Tutkimus jatkuu ja vuoden 2012 kokeessa tarkastellaan kasvuston mikroilmastollisia eroja. 


\section{Johdanto}

Öljykasvien viljelyala oli 1970-luvulla 32000 ha ja se kasvoi 1980 luvun aikana lähes 80000 hehtaariin. Vuonna 2010 viljelyala oli ennätyksellinen 158000 ha, josta rypsiä oli 141500 ha. Öljykasvien viljelyalan toivotaan lisääntyvän jopa 200000 hehtaariin, mutta kesäksi 2011 viljelyala puoliintui ollen 79000 ha (Matilda maataloustilastot 2011).

Rypsin viljelyn laajentuessa uusille alueille satotasot ovat viimeisen 15-20 vuoden aikana kuitenkin laskeneet. Kasvien hintavaihteluiden lisäksi viljelyintoa on vähentynyt jopa alle $1000 \mathrm{~kg} / \mathrm{ha}$ jääneet sadot. Syyksi on esitetty: mm. maan tiivistymistä, tuholaisia, lisääntynyttä tautipainetta, viljelykierron lyhyyttä ja uusien lajikkeiden satoherkkyyttä kukintavaiheen lämpötiloille (Peltonen-Sainio ym. 2007; Hannukala ym.2008a ja 2008b; Rypsinoste loppuraportti). Peltonen-Sainio ym. (2007) mukaan realistinen sato kevätrypsille olisi $2100 \mathrm{~kg} / \mathrm{ha}$.

Tutkimuksen alkaessa v. 2009 rypsin tavanomainen kylvösuositus oli n. 8-10 kg/ha (300-350 $\mathrm{kasvia} / \mathrm{m}^{2}$ ). Kyseinen siemenmäärä voi heikosti taimettuvilla savimailla olla sopiva. Muodostuuko kyseisellä siemenmäärällä liian tiheä kasvusto hikevillä hietamailla ja multamailla. Tiheässä kasvustossa mikroilmasto on kostea ja tautiriski kasvaa. Johtaako kilpailu honteloihin ja pitkiin yksilöihin? Pohjanmaalla moni viljelijä käyttääkin 6-8 kg/ha ja pienistä, jopa 4 kg/ha kylvömääristä on hyviä kokemuksia. Tutkimushankkeessa on julkaistu yksi opinnäytetyö (Haavisto,T. 2011) ja kaksi valmistuu v. 2012 (Laakso, T. sekä Rintamäki, M).

\section{Tutkimushypoteesit:}

1 Kylvötiheys (kasvitiheys) vaikuttaa kasvuston eri kehitysvaiheiden kestoon ja ajoittumiseen, kasvuston rakenteeseen, kasvuston kosteuteen, tautipaineeseen, lakoon ja satoon.

2 Harvassa kasvustossa kasvin juuristo muodostuu laajemmaksi - poudankesto paranee

3 Harvassa kasvustossa päävarret voivat olla lyhyempiä ja paksumpia, sivuhaaroja on enemmän ja lakoutuminen voi olla vähäisempää ja tapahtua myöhemmin.

4 Pahkahome ei tuhoa isoissa kasveissa johtojänteitä yhtä rajusti, kuin tiheässä kasvaneissa honteloissa kasveissa.

\section{Aineisto ja menetelmät}

Tutkimusta on tehty kolmena vuotena koulutilan rypsin talousviljelmällä, sekä vuonna 2011 Ylistarossa multamaalla, jonka taimettuminen on ollut aina hyvä. Kokeessa rypsilajikkeiden kylvösiemenmäärät vaihtelivat itävyyden ja tuhannen siemenen paino perusteella välillä 2-8,3 kg/ha (Taulukko 1), tiheystavoitteet olivat eri vuosina välillä 62-300 kpl/m² (Taulukko 2). Koulutilan lohkot ovat multavia hienohietamaita (mHHt) ja niiden viljavuusluvut ovat tyydyttäviä ja hyviä.

Kokeessa oli kolme kerrannetta ja koejäsenet arvottiin. Eri koevuosina koeruudun koko vaihteli 0,1-0,5 ha välillä. Lannoitus tehtiin ympäristötukiehtojen mukaisesti $1750 \mathrm{~kg} / \mathrm{ha}$ satotason mukaan. Kylvö, hoitotyöt ja sadonkorjuut tehtiin osana opetusta, siksi ei aina päästy ihanneajoitukseen. Kylvö tehtiin Junkkari Super seed 3000 kylvökoneella. Oikea siemenmäärä varmistettiin useilla kiertokokeilla. Kasvinsuojelu tehtiin Amazone 1000 kasvinsuojeluruiskulla ja puinti Sampo Rosenlew 2045 leikkuupuimuri. Sato punnittiin kuivurilla olevalla vaa'alla. Kosteus mitattiin Wile 55 kosteusmittarilla ja sato muutettiin vastaamaan $9 \%$ kosteutta. Ruutusadoista otettiin näytteet, jotka kuivattiin yrttikuivurissa nailonpussissa. Näytteiden laatu analysoitiin v. 2009 ja 2010 Eurofins laboratoriossa.

Taimettuminen laskettiin kesäkuun puolivälin jälkeen kaikista koeruuduista kerranteittain10-20 satunnaistetusta kohdata $80 \mathrm{~cm}$ matkalta. Kasvuston satokomponentit, sivuhaarat ja litujen lukumäärä päähaarassa laskettiin elokuun loppupuolella tai sadonkorjuun yhteydessä otetuista näytteestä. Varren paksuus mitattiin työntömitalla $10 \mathrm{~cm}$ juurenniskan yläpuolelta tai alimman haaran alapuolelta. Tuloksista laskettiin keskiarvot, jotka esitetään koejäsenittäin. Pahkahomeet laskettiin sadonkorjuun jälkeen koejäsenittäin neljältä $1 \mathrm{~m}^{2}$ koealalta kaikista kerranteista ja niistä laskettiin keskiarvot. Tuhannen siemenen painot määritettiin vastaavasti punnitsemalla jokaisesta otetuista näytteestä neljä 100 siemenen erää. 
Taulukko 1. Kokeen rypsilajikkeet ja tuhannen siemenen painot (tsp), kylvömäärät sekä kylvö- ja sadonkorjuuajat

\begin{tabular}{|c|c|c|c|c|c|c|c|c|c|}
\hline & lajike & itävyys \% & tsp g & & ömä & $\mathrm{kg} / \mathrm{ha}$ & & kylvöpäivä & puintipäivä \\
\hline Ilmajoki 2009 & Eos & 88 & 2,6 & 2 & 4 & 6 & & 25.5 . & 30.9 . \\
\hline 2010 & Cordelia & 99 & 2,74 & 2,8 & 4,2 & 5,5 & 8,3 & 2.6. & 9.9. \\
\hline 2011 & Pepita & 88 & 2,25 & 2,6 & 3,9 & 5,2 & 7,8 & 26.5. & 5.10 . \\
\hline Ylistaro 2011 & Cordelia & 95 & 2,3 & & 4,5 & 6 & & 21.5. & 30.9. \\
\hline
\end{tabular}

\section{Kasvukausien säät}

Kasvukauden 2009 toukokuu oli kuiva, kuun puolivälin sade viivytti rypsin kylvöjä koulutilalla. Kesäkuukin oli kuiva ja alkupuolella oli tosin viileä jakso, silti rypsit taimettuivat aluksi harvakseltaan ja epätasaisesti. Heinäkuukin oli kuiva. Kukintaa ennen oli kuiva ajanjakso mikä ei edellyttänyt pahkahomeen torjuntaa.

Vuonna 2010 toukokuun runsaasta sateesta pääosa tuli kuun viimeisellä kolmanneksella myöhästyttäen kylvölle menoa. Kesäkuu oli kuiva ja heinäkuu oli lämmin ja sateet tulivat pääosin loppukuusta. Koko elokuu oli runsassateinen.

Kasvukaudella 2011 kylvö jäi myöhäiseksi toukokuun puolivälin sateiden viivästyttäessä kylvöjä. Kesäkuu sateet tulivat puolikuun jälkeen. Alkukesästä kuivuus ja kirpat vaikuttivat kasvuston tiheyteen. Kesän loppu ja syksy olivat sateiset ja sadonkorjuu viivästyikin niiden vuoksi 2-3 viikkoa kuten v. 2009. Koejakson kuukausien keskilämpötilat ja -sademäärät on esitelty tarkemmin taulukossa 2.

Taulukko 2. Tutkimuskesien kuukausien keskilämpötilat ja -sademäärät Ilmajoella sekä keskimääräiset normaalikauden arvot Ylistaron tutkimusasemalta, joka sijaitsee koulutilasta n. 20 km päässä.

\begin{tabular}{lcccccccc}
\hline \multicolumn{1}{c}{ Ilmajoki } & $\begin{array}{c}2009 \\
{ }^{\circ} \mathrm{C}\end{array}$ & Sade mm & $\begin{array}{c}2010 \\
{ }^{\circ} \mathrm{C}\end{array}$ & Sade mm & $\begin{array}{c}2011 \\
{ }^{\circ} \mathrm{C}\end{array}$ & Sade mm & ${ }^{\circ} \mathrm{C}$ & $\begin{array}{c}\text { Ylistaro1971-2000 } \\
\text { Sade mm }\end{array}$ \\
\hline Toukokuu & 15,1 & 41 & 11,6 & 81,5 & 10,2 & 45,5 & 8,9 & 33 \\
Kesäkuu & 13,9 & 28,5 & 13,7 & 49,5 & 16,6 & 52 & 13,9 & 53 \\
Heinäkuu & 16,2 & 53 & 20,5 & 54,5 & 19,1 & 147 & 15,8 & 73 \\
Elokuu & 15,3 & 77 & 15,7 & 96,5 & 15,6 & 88,5 & 13,8 & 62 \\
Syyskuu & 11,4 & 29,5 & 9,9 & 67,5 & 11,9 & 113,5 & 8,7 & 59 \\
\hline
\end{tabular}

\section{Tulokset ja tulosten tarkastelu \\ Taimitiheys ja sadot}

Kaikkia tässä tutkimuksessa toteutuneita kasvustotiheyksiä (55-249 kpl/m²) Ilmajoella voidaan pitää suositeltuun tavoitetiheyteen nähden harvana. Koelohkojen keskisadot olivat $1640-2690$ kg/ha (taulukko 3) ja olivat alueen keskisatoja korkeampia (Matilda maataloustilasto).

Vuonna 2009 kasvustojen tiheydet olivat 2, 4 ja 6 kg/ha kylvöillä 55, 110 ja 145 kpl/m2. Suurin sato 2684 kg/ha (9 \% kosteus) oli keskimmäisellä kylvömäärällä, muut koejäsenet jäivät siitä vajaan 100 kg/ha. Harvassa kasvustossa tyvien paksuus oli 8,7 mm ja tiheimmässä 5,5 mm, sivuhaarojen lukumäärä ja niiden litujen lukumäärä kompensoivat yksilömäärää. Joka toisesta vantaasta kylvetyllä pienimällä kylvömäärällä roskaisuus oli kaksinkertainen muihin koejäseniin nähden. Puintikosteus ja sadon laatu eivät eronneet toisistaan, kun roskaisuus huomioidaan.

Kuivana kesänä 2010 taimiluku oli kerranteissa I ja II keskimäärin 88, 139, 156 ja 249 kpl/m2. Suurin kylvömäärä oli 8,3 ja pienin 2,8 kg/ha. Sadot olivat välillä 1960-2 100 kg/ha. Varsien paksuudet olivat 6,3-4,1 mm. Eri kasvutiheyksissä sivuhaarojen lukumäärässä ei ollut eroja. Päävarsien litumäärässä ei ollut eroja. Harvassa kasvustossa sivuhaarojen keskimääräinen litumäärä oli yli kaksinkertainen harvaan kasvustoon nähden. Kesällä 2011 sato tiheimmässä kasvustossa (170 kpl/m2) oli 1640 kg/ha ja muissa $1890-2060$ kg/ha. Rypsin kylvöajat koulutilalla olivat kaikkina vuosina viikon - kaksi myöhemmin kuin pääosalla alueen viljelijöistä, mikä todennäköisesti alensi taimettumisprosenttia. Kasvukauden 2009 sää oli keskimäärin hyvä rypsin kasvun kannalta. Kasvukausi 2010 oli lämmin ja kuiva ja kuivuus pakkotuleennutti ja verotti satoa. Kasvukaudella 2011 alkukesästä kuivuus ja kirpat (kaksi torjuntaa) vaikuttivat kasvuston tiheyteen. Kesän loppu ja syksy olivat sateiset ja sadonkorjuu viivästyikin niiden vuoksi 2-3 
viikkoa kuten v. 2009. Ylistaron multamaalla taimettuminen oli aikaisemman kylvön (taulukko 1) vuoksi hyvä ja taimimäärät olivat korkeita (viljelijän arvio taimettumisesta $95 \%, 180$ ja $240 \mathrm{kpl} / \mathrm{m}^{2}$ ), kasvusto lakoontui ja sato jäi kesällä 2011 alhaiseksi1000 kg/ha (Taulukko 3). Tiheästä kasvustosta kuolee yksilöitä kesän aikana. Pahkala ym. (1994) havaitsivat rapsilla savimaalla, että tavoitetiheydestä 450 saavutettiin maksimissaan 300 ja lisäksi tuleentumisaikana jäljellä oli maksimissaan 150 kasvia.

Myös Pohjois-Amerikan ja Kanadan keskilännessä semiarideilla alueilla kasvukauden lyhyys rajoittaa viljelyä, sielläkin tutkitaan rapsilla kylvötiheyden vaikutuksia vastaavanlaisissa kevään haasteissa kuin meillä Suomessa (Angadi ym. 2003; Lamb ym. 2004; Chen ym. 2005; Hanson ym. 2008). (Maanpinnan korkeuden noustessa merenpinnasta 100 m laskee lämpötila $0,6-1{ }^{\circ} \mathrm{C}$, alueiden korkeudet merenpinnasta 400-1200 m, vertailu oloihimme on siksi mahdollista). Siellä rapsin kylvösuositus on $80-180 \mathrm{kpl} / \mathrm{m}^{2}$ (5,6-9 kg/ha, tsp 4,3 g), jolla saadaan yleensä paras sato. Alhaisten taimimäärien vaikutusta selvittävässä kokeessa saatiin kylvötiheydellä $40 \mathrm{kpl} / \mathrm{m}^{2}$ sama sato kuin $80 \mathrm{kpl} / \mathrm{m}^{2} \mathrm{kylvöllä} \mathrm{(Angadi} \mathrm{ym.} \mathrm{2003).} \mathrm{Chen}$ ym. (2005) totesivat aikaisessa kylvössä 32 ja 65 siementä/m² paremmaksi kuin 97 siemenen kylvömäärän kuivissa ja lämpöisissä oloissa. Hanson ym. (2008) testasivat kylvötiheyksiä 54-216 kpl/m² parhaat sadot tuli suosituksen mukaisilla ja sato laski alimmalla taimitiheydellä $14 \%$.

Taulukko 3. Taimitiheys, varrenpaksuus ja sato Ilmajoella kolmena ja Ylistarossa yhtenä koevuotena, sekä sadon laatu Ilmajoella kahtena vuotena. Ylistarossa taimettuminen oli viljelijän mukaan $95 \%$, esitetyt luvut *) kuvaavat sängestä kaksiviikkoa sadonkorjuun jälkeen laskettuja ja analysoituja varsia.

\begin{tabular}{lccccccc}
\hline & Taimia/m2 & $\begin{array}{c}\text { Varren pak- } \\
\text { suus mm }\end{array}$ & $\begin{array}{c}\text { Sato 9 \% } \\
\text { kosteus }\end{array}$ & $\begin{array}{c}\text { Lehtivihreä } \\
\text { ppm }\end{array}$ & Tsp & Roska \% & Öljy \% \\
\hline 2009 & 55 & 8,7 & 2587 & 5 & 2,5 & 9,2 & 37,5 \\
Ilmajoki & 110 & 7,3 & 2684 & 5 & 2,69 & 4,7 & 38,9 \\
& 145 & 5,5 & 2595 & 5 & 2,76 & 4,4 & 39,1 \\
\hline 2010 & 88 & 6,3 & 1963 & 5 & 2,45 & 1,1 & 40,1 \\
& 139 & 4,8 & 2043 & 5 & 2,45 & 1 & 40,1 \\
& 156 & 4,5 & 2097 & 6 & 2,43 & 1 & 39,9 \\
& 249 & 4,1 & 1959 & 5 & 2,59 & 0,9 & 40,6 \\
\hline 2011 & 52 & 7,8 & 1889 & & & & \\
& 70 & 8,1 & 1926 & & & & \\
\hline Ylistaro & 92 & 7,0 & 2062 & & & & \\
\hline
\end{tabular}

\section{Satokomponentit:taimettumisprosentti, pituus, päävarret haarat ja lidut}

Taimettuminen vaihteli 46-92 \% välillä ja oli runsainta keväällä 2010. Taimettuminen oli pienillä kylvömäärillä hieman suuria parempi. Kanadassa rapsin taimettumisprosentti oli 48-100 \% ja oli 19 mm kylvösyvyydellä keskimäärin n. 30 \% korkeampi kuin 38 mm syvyydestä (Hanson ym. 2008).

Taimettumisnopeudessa ei ollut eroa, mutta harvemmat kasvustot sulkeutuivat myöhemmin. Harvemmassa kasvustossa varsien pituuskasvu ja kukinta alkoivat päivän - pari myöhemmin. Kasvuvaiheissa vastaava ero oli ajoittain havaittavissa. Koeruutujen kasvustojen pituudet olivat v. 2009120 cm, ja v. 2010 95-100 cm sekä v. 2011 110-120 cm. Kyseisillä kasvustotiheyksillä kasvustoilla ei ollut pituuseroja. Vuonna 2011 talousviljelmällä oli kahden kylvökoneleveyden vertailusoiro, jossa kasvustotiheys oli 220 $\mathrm{kpl} / \mathrm{m}^{2}$ ja siinä kasvustokorkeus oli koeruutuja alhaisempi 100-110 cm.

Harvassa kasvustossa sivuharoja muodostui kaksinkertainen määrä tiheisiin kasvustoihin verrattuna, sen lisäksi niihin muodostui lituja enemmän, harvassa kasvustossa myös päähaaran muodostui enemmän lituja (Taulukko 3). Varren paksuus oli harvassa kasvustoissa paksumpia kuin tiheissä. Pahkala ym. (1994) mukaan myös rapsilla sivuhaarojen määrä ja niiden litujen lukumäärä lisääntyy kasvuston harvetessa ja myös päävarren litumäärä lisääntyy, yli $150 \mathrm{kpl} / \mathrm{m}^{2}$ taimitiheyksillä muutos hidastuu. Rapsilla savimaalla tavoitetiheydestä 450 saavutettiin maksimissaan 300 ja lisäksi tuleentumisaikana jäljellä oli maksimissaan 150 kasvia. Myös rapsilla varret olivat harvemmassa kasvustossa paksumpia ja kasvusto jopa hieman lyhyempää, tuleentuminen kuitenkin hidastuu jos kasvustotiheys on alle $150-200 \mathrm{kasvia} / \mathrm{m}^{2}$ (Pahkala ym. 1994). Kasvuston ollessa hyvin tiheä sivuhaaroja ei muodostu lainkaan ja päävarsi lyhenee ja litumäärä laskee ja sato tuleentuu nopeasti (Pahkala ym. 1994). Rypsin kasvutiheyssuositus on $50 \mathrm{kpl} / \mathrm{m}^{2}$ enemmän kuin rapsilla. 
Siemenkoossa, eri kasvutiheyksillä, ei vuonna 2010 olut eroja ja vuonna 2009 erot olivat hyvin pienet. Peltonen-Sainio ja Jauhiainen (2008) mukaan MTT:n lajikekoe-aineistossa suuremmissa satoluokissa neliömetriltä tuotettu siemenmäärä on suurempi, mutta siementen painoissa ei ole eroja ja huippusatoja saavutetaan erilaisilla siemenpaino- ja määrä-yhdistelmillä. MTT:n aineistossa ei kukinnan alkamiseen kuluvassa ajassa, kukinnan kestossa, eikä siemenenmuodostumisajan välillä ei ollut eroa eri satoluokissa (Peltonen-Sainio ja Jauhiainen 2008). Ilmajoen kokeet antavat viitteitä siitä, että satokomponenttien ja vararavintopaikkojen synnylle olisi harvassa kasvustossa enemmän aikaa. Lajikekokeiden ruutuvälit ja kerrannevälit antavat lisätilaa, joka voi johtaa erilaiseen kehitysrytmiin ja kasvustorakenteeseen, kuin vastaava kasvutiheys talousviljelmillä. Harvimmissa kasvustoissa kylvön ollessa epätasaista isojen yksilöiden tuleentuminen kuitenkin hidastui Ilmajoen kokeessa.

Ensimmäisenä koevuotena rikkakasvien torjunta epäonnistui ja joka toisesta vantaasta kylvetty harvin kasvusto kärsi rikkakasveista eniten. Sadon öljypitoisuudessa ei kuitenkaan ollut eroa (Taulukko 3), kun roskaisuus rikkakasvien vaikutus huomioidaan. Juurten tuorepainot elokuun 11. vuonna 2010 olivat harvimmassa kasvustossa suurin 2, 5 g ja seuraavat olivat 1,4 g ja 1,9 g suurimmassa kasvutiheydessä juuren paino oli pienin $0,9 \mathrm{~g}$.

Taulukko 4. Rypsin tärkeimmät satokomponentit eri kasvustotiheyksillä sekä taimettumisprosentit.

\begin{tabular}{lccccccccccc}
\hline \multicolumn{1}{c}{ vuosi } & 2009 & \multicolumn{1}{c}{2010} \\
\hline Tavoite kpl/m & 68 & 135 & 203 & 100 & 150 & 200 & 300 & 100 & 150 & 200 & 300 \\
Taimitiheys & 55 & 110 & 145 & 88 & 139 & 156 & 249 & 52 & 70 & 92 & 170 \\
Taimettumis \% & 81 & 81 & 71 & 88 & 92 & 78 & 83 & 52 & 46 & 46 & 57 \\
Varrenpaksuus & 8,7 & 7,3 & 5,5 & 6,3 & 4,8 & 4,5 & 4,1 & 7,8 & 8,1 & 7 & 5,9 \\
Sivuhaarat/kasvi & 5,4 & 3,3 & 2,5 & 6,2 & 4,9 & 4,6 & 2,2 & & & & \\
Lidut/päähaara & 39,4 & 37,6 & 30,7 & 24 & 23 & 22 & 24 & & & \\
Lidut/sivuhaara & 37,3 & 20,5 & 15,7 & 30 & 41 & 40 & 14 & & & \\
Lidut/kasvi & 240 & 105,2 & 70,6 & 138 & 70,5 & 76,6 & 36,7 & & & \\
\hline
\end{tabular}

\section{Pahkahome ja lako}

Syksyllä 2009 ei havaittu pahkahomeen pahkoja, kasvusto oli pystyä tai taipunut 20- 30 asteen verran. Syksyllä 2010 kasvusto oli edellisvuotta harvempaa, matalampaa, pakkotuleentunutta, pystyä ja paikoin 15-20 astetta taipunutta. Pahkahomeen pahkoja löytyi keskimäärin $6-8 \mathrm{kpl} / \mathrm{m}^{2} \mathrm{kun}$ pahkahome oli torjuttu ja torjumattomilta koejäseniltä harvimmasta kasvustosta $15 \mathrm{kpl} / \mathrm{m}^{2}$ ja muista kasvustoista $25-27$ $\mathrm{kpl} / \mathrm{m}^{2}$.

Syksyllä 2011 pahkoja oli runsaasti sekä Ylistarossa että Ilmajoella. Kuivan kesäkuun jälkeen heinäkuu oli alusta lähtien runsassateinen. Ylistarossa pahkahome ruiskutus oli suoritettu 7.7, jolloin ensimmäiset terälehdet olivat alkaneet varista. Kasvusto pysyi pystyssä vielä 2-3 viikkoa ruiskutuksen jälkeen eli kukinnan loppuun saakka. Elokuun alkupuolella kasvusto oli kauttaaltaan laossa, $10-20 \mathrm{~cm}$ kohollaan, ja tähän vahvana tekijänä voidaan pitää rankkoja sateita. Sademäärä oli 5.8. n.50mm ja 6.8. n.40mm. Lakoontumiseen on varmasti vaikuttanut myös 16-17.7. sade jolloin vettä tuli n. $26 \mathrm{~mm}$ sekä 22.7. kova tuuli sekä $30 \mathrm{~mm}$ sade. Ylistarossa pahkahomeen pahkoja oli jäljellä olevissa varsissa harvemmassa kasvustossa $29 \mathrm{kpl} / \mathrm{m}^{2}$ ja tiheämmässä kasvustossa $32 \mathrm{kpl} / \mathrm{m}^{2}$

Ilmajoella säät olivat hyvin samanlaiset, Runsaiden sateiden märkänä pitävälle pellolle päästiin pahkahomeruiskutuksen täyden kukinnan aikaan15.7.. Ilmajoella heinäkuun 16-17. pv. sademäärä oli 20 mm ja 24. pv 34 mm, elokuun 5. ja 6 pv sateet olivat 25 ja 27 mm. Syksyllä 2011 kasvusto oli kauttaaltaan laossa, mutta se oli pääosin kohollaan 20-40 cm irti maasta. Ilmajoella pahkahomeen pahkoja oli keskimäärin 2-6 kpl $/ \mathrm{m}^{2}$ kolmessa pienimmässä kasvutiheydessä ja $15 \mathrm{kpl} / \mathrm{m}^{2}$ suurimmassa. Torjumattomilta koejäsenistä kahdesta harvimmasta kasvustosta pahkoja löytyi 13 ja $12 \mathrm{kpl} / \mathrm{m}^{2}$ ja toiseksi tiheimmästä 20 $\mathrm{kpl} / \mathrm{m}^{2}$ ja tiheimmistä $27 \mathrm{kpl} / \mathrm{m}^{2}$. Pahkahome on myös ongelma Pohjois-Amerikassa ja Lamb ym. (2004) toteavatkin mikroilmaston olevan suotuisan pahkahometartunnalle tiheämmässä (18 \%) kuin harvemmassa kasvustossa (0\%).

Hikevillä mailla tiheissä kasvustoissa esiintyy pahkahometta myös vuosina, jolloin kukintaa edeltävä kolmen viikon ajanjakson 30 mm sateen kynnysarvo ei ylity, tästä esimerkkinä Ilmajoki kesällä 2010 ja aiempien satovuosien kokemukset Ilmajoen ja Ylistarosta eri lohkoilta. Varsinkin kasvuston lakoontuessa pahkahomeen tiedetään alentavan sadon jopa puoleen. 


\section{Johtopäätökset}

Hikevillä ja taimettumisolosuhteiltaan hyvillä mailla rypsin tavoitetiheytenä voidaan pitää 150-200 $\mathrm{kpl} / \mathrm{m}^{2}$. Itävyydestä ja tuhannen siemen painosta riippuen ky1Pienestä taimimäärästä on myös hyötyä poutivilla mailla, sillä pienellä kasvutiheydellä kasvin juuri on isompi ja silloin kasvi pystyy hyödyntämään suuremman maatilavuuden vesivaroja, eikä kasvukauden alussa ole turhaa haihduntaa. Tiheässä kasvustossa vettä ja energiaa kuluu myös kilpailussa häviävien kasvien kasvatukseen ja toistensa varjostukseen. Taimitiheyksillä alle $100 \mathrm{kpl} / \mathrm{m}^{2}$ saadaan myös hyviä satoja, mutta tuleentuminen hidastuu varsinkin epätasaisesti jakaantuneessa kasvustossa, jossa kasvaa suuria yksilöitä, joiden kehitysrytmi ja tuleentuminen hidastuvat. Rypsille sadon tuleentumisen pienestä viivästymisestä ei ole niin suurta haitta kuin rapsilla sillä niiden kasvuaika on n. 100 pv ja rapsilajikkeiden kasvuaika on 110 pv. Tutkimuksen aikana viljelyohjeita onkin päivitetty ja yleissuosituksena esitetään $6-10 \mathrm{~kg} / \mathrm{ha}\left(300 \mathrm{kpl} / \mathrm{m}^{2}\right)$, hyvissä olosuhteissa suositellaan käytettäväksi $4-5 \mathrm{~kg} / \mathrm{ha}$ ja taulukossa esitetään jopa pienempienkin kylvömäärien vaikutusta kasvustotiheyteen (Öljykasvinviljelijän opas 2011).

Omiin rypsiviljelmiin kannattaa paneutua, suunnitella kylvömäärät itävyyden, tuhannen siemenen painon, lohkon ja kevään olojen perusteella. Kylvösyvyys tulee säätää olosuhteiden mukaan oikeaksi. Toimenpiteet on syytä kirjata muistiin, taimimäärät ja tiheydet on hyvä laskea useasti ja vielä sadonkorjuun jälkeen laskea yksilömäärät. Kirjatuista havainnoista saa lähtöainesta seuraavien kasvukausien rohkeisiinkin kokeiluihin.

Kiitokset Oiva Kuusisto Säätiölle, joka on tuellaan mahdollistanut tutkimuksen toteuttamisen. Kiitokset myös koulutilan työnjohdolle, työntekijöille ja harjoittelijoille, jotka ovat vastanneet viljelystä ja hoitotoimenpiteistä, sekä opiskelijoille, jotka ovat olleet mukana tutkimuksen käytännön toteutuksessa sekä aineiston keräämisessä.

\section{Kirjallisuus}

Angadi, S V., Cutforth, H. W., McConkey, B. G., \& Gan, Y. 2003. Yield adjustment by canola grown at different plant populations under semiarid conditions. Crop Science 43: 1358-1366

Chen, C., Jackson, G. Karnes, N., \& Wichman, D. 2005. Determining the Feasibility of Early Seeding Canola in the Northern Great Plains. Agronomy Journal 97: 1252- 1262

Hannukkala, A., Laitinen, P. \& Peltonen-Sainio, P. 2008a. Rypsin tautikartoitus ja tautien torjunta. Teoksessa: Heikki Jalli, toim. Kasvinsuojelupäivä, Jokioinen 22.1.2008. Kasvinsuojeluseura. p. 18-20.

Hannukkala, A., Laitinen, P. \& Peltonen-Sainio, P. 2008b.Rypsin hankala tautikesä. Maatilan Pirkka 1/2008: 20-21

Hanson, B., Johnson, B., Henson, R. \& Riveland, N. 2008. Seeding Rate, Seeding Depth, and Cultivar Influence on Spring Canola Performance in the Northern Great Plains. Agronomy Journal 100:1339-1346.

Jackson, C., Karnes, N., \& Wichman, D. 2005. Determining the Feasibility of Early Seeding Canola in the Northern Great Plains. Agronomy Journal 97:1252- 1262

Kangas, A. Laine, A. Niskanen, M. Salo, Y. Vuorinen, M. Jauhiainen, L. \& Nikander, H. 2010. Virallisten lajikekokeiden tulokset 2003-2010.http://www.mtt.fi/mttkasvu/pdf/mttkasvu13.pdf

Lamb, K., \& Burton, J. 2004. Seed Size and Seeding Depth Influence on Canola Emergence and Performance in the Northern Great Plains. Agronomy Journal 96: 454-461

Matilda maataloustilastot 2011. http://www.maataloustilastot.fi/satotilasto

Pahkala, K., Sankari, H. \& Ketoja, E. 1994. The Relation between Stand Density and the Structure of Spring Rape (Brassica Napus L.). Journal of Agronomy and Crop Science 172: 269-278.

Peltonen-Sainio, P., Jauhiainen, L. \& Hannukkala. A. 2007. Declining rapeseed yields in Finland: how, why and what next? Journal of Agricultural Science 145: 587-598.

Peltonen-Sainio, P. \& Jauhiainen, L. 2008. Association of growth dynamics, yield components and seed qualityin long-term trials covering rapeseed cultivation history at high latitudes. Field Crops Research 108: 101-108 Rypsinoste loppuraportti. 2010. Toimenpiteet öljykasvituotantomme kilpailukyvyn parantamiseksi: satotason ja viljelyalan nostaminen (RYPSINOSTE). http://www.agronet.fi/rypsi2000/index_linkit.html Öljykasvinviljelijän opas 2011. http://www.agronet.fi/rypsi2000/ 